\title{
The Socio-Demographic and Clinical Profile of Individuals with Autism Spectrum Disorder in a Tertiary Care Teaching Hospital in South India
}

\section{Original Article}

\section{Nithya HM, Kannan PP, Sudhakar S}

-Department of Psychiatry, Chengalpattu Medical College Hospital

\section{Srinivasan $\mathbf{R}$}

-National Institute for Research in Tuberculosis, ICMR.

\section{Abstract}

\section{BACKGROUND}

Autism spectrum disorder (ASD) is an neuro-developmental disorder. There is a paucity of epidemiological data on ASD in India. This study is an attempt to understand the socio demographic and clinical characteristics of the individuals with ASD.

METHODS

The case records were perused to extract the datas.

\section{RESULTS}

The study revealed that two third of individuals with ASD also have Intellectual Disability, more than half the mothers of individuals with ASD did not breastfeed beyond 12 months, about one third of individuals with ASD have not availed any kind of services. It takes arounds 6 years of age for the parents/ individuals with ASD to seek treatment help.

\section{CONCLUSION}

Understanding the profile is essential for better treatment planning.

\section{Corresponding author :}

Nithya HM,

Assistant Professor of Psychology cum Clinical Psychologist,

Chengalpattu Medical College Chengalpattu, Tamilnadu - 603001.

Email: nithyahm@gmail.com

\section{KEY WORDS: Autism Spectrum Disorders, India, Clinical Profile}

RUNNING TITLE: Profile of Individuals with Autism Spectrum Disorder 


\section{INTRODUCTION}

Autism spectrum disorder (ASD) is a neurodevelopmental disorder. The individuals with ASD have the symptoms of persistent deficits in social communication and social interaction and have restricted repetitive patterns of behavior, interests or activities. These symptoms are present in the early developmental periods and it causes clinically significant impairment in social, occupational or other important areas of functioning in their lives. ${ }^{(1)}$ The disorder has a huge impact not only on the individual but on the family as well. There has been an increase in the prevalence of ASD in India. ASD was once considered rare but now it has become apparent that it is a more common developmental disability than previously thought. The increased prevalence could be due to advanced parental age at conception and perinatal risks like prematurity and now high risk infant survival rate has also increased. There is a paucity of epidemiological data on ASD in India. Depending on the screening tools and the area surveyed, the estimated prevalence of ASD in India ranges from $0.15 \%$ to $1.01 \% .^{(2,3)}$ The prevalence of ASD in the rural areas was $0.90 \%$, while in the hilly regions it is $0.6 \%$, in the urban areas it is $1.01 \%$, in the tribal areas it is $0.1 \%$ and in coastal regions it is $0.61 \% \cdot{ }^{(3)}$ As there is sparse information available on the clinical and social profile of the individuals with ASD, this study was carried to identify the demographic characteristics of individuals with ASD and factors associated with severity of ASD.

\section{MATERIALS AND METHODS}

Case records of patients diagnosed with ASD in the period from April 2013 - July 2019 in the Department of Psychiatry of Chengalpattu Medical College Hospital were reviewed. The data related to the demographic and diagnostic interview details and test results of Childhood autism rating scale (CARS), Vineland Social Maturity Scale (VSMS) and for the patients who were verbal, Binet-Kamat Test of Intelligence (BKT) results were extracted from the case records.

Childhood autism rating scale (CARS): CARS is a diagnostic instrument and it assesses the severity of autism. It has 15 items which addresses the different domains of ASD. Each of the items are rated from 1 to 4. The total score ranges from 15 to 60 and the cut off for the diagnosis of ASD is 30. The scores from 30 to 36.5 indicates mild to moderate autism and above that indicates severe autism. ${ }^{(4)}$ The psychometric property of CARS has been well documented in Indian population. ${ }^{(5)}$

Vineland Social Maturity Scale (VSMS): VSMS is used to assess the social and adaptive functions and also the social competency of individuals. When standard intelligence tests cannot be administered due to impaired speech or poor cooperation VSMS is preferred. The VSMS has 8 domains: self-help general, self-help eating, self-help dressing, locomotion, communication, occupation, self-direction and socialisation. The social age is obtained.

Binet-Kamat Test of Intelligence (BKT): BKT is a modified version of Stanford Binet Scale and is used for measuring intelligence. It is an age scale and can be administered from 3 years of age. It includes both verbal and performance tests. It has both power and speed test. The intelligence quotient is obtained by dividing mental age by chronological age.

The data was analysed statistically using the SPSS 20. The frequency, mean, median, standard deviation and chi square were used. The level of significance was set at 0.05 level. 
Table 1: Socio-Demographic Profile of Individuals with ASD

\begin{tabular}{|l|c|}
\hline Variable & N Frequency (\%) \\
\hline Gender & \\
\hline Male & $118(86.1)$ \\
\hline Female & $19(13.9)$ \\
\hline Marriage relationship of parents & \\
\hline Consanguineous & $30(21.2)$ \\
\hline Non-consanguineous & $107(77.1)$ \\
\hline Adopted & $1(0.7)$ \\
\hline Birth order & \\
\hline First & $81(59.1)$ \\
\hline Second & $45(32.8)$ \\
\hline Third & $8(05.8)$ \\
\hline Sixth & $1(00.7)$ \\
\hline Father's Job & $109(79.6)$ \\
\hline Agriculturist & $4(02.9)$ \\
\hline Daily wager & $13(09.5)$ \\
\hline Business & $5(03.6)$ \\
\hline Private sector & \\
\hline Government sector & $9(03.6)$ \\
\hline Self employed & $9(06.6)$ \\
\hline Not available & $21(15.3)$ \\
\hline Mother's Job & \\
\hline Agriculturalist & \\
\hline Daily wager & $(02.8)$ \\
\hline Business & \\
\hline Private sector & \\
\hline Government sector & \\
\hline Homemaker & \\
\hline Not available & \\
\hline
\end{tabular}

Table 1, shows the sociodemographic profile of the individuals with ASD, majority (86.1\%) were males in the study. Nearly three fourth were born out of non-consanguineous union and 59.1\% were first born. With regard to occupation of their parents, $58.4 \%$ of the fathers were working in the private sector and majority of the mothers were homemakers. 
Table 2: Clinical Profile

\begin{tabular}{|l|l|l|}
\hline Variable & \multicolumn{1}{|c|}{ N (\%) } & Mean \pm SD \\
\hline Autism with intellectual disability & $87(63.5)$ & \\
\hline Autism without intellectual disability & $16(11.7)$ & \\
\hline Global developmental delay & $34(24.8)$ & \\
\hline Autism with speech impairment & $124(90.5)$ & \\
\hline Autism without speech impairment & $13(09.5)$ & \\
\hline Severity of autism & & \\
\hline \multicolumn{1}{|c|}{ Mild - moderate } & $123(89.8)$ & \\
\hline \multicolumn{1}{|c|}{ Severe } & $14(10.2)$ & \\
\hline CARS scores (Mean \pm SD) & & $33.63 \pm 02.97$ \\
\hline Social age in months (Mean \pm SD) & & $36.39 \pm 14.43$ \\
\hline IQ (Mean \pm SD) & & $81.30 \pm 16.79$ \\
\hline Seizures & $27(19.7)$ & \\
\hline On antiepileptic drugs & $13(08.8)$ & \\
\hline Family h/o mental illness & $23(16.8)$ & \\
\hline
\end{tabular}

Table 2, shows the clinical profile, it has been found that nearly two third of the individuals in the study had intellectual disability and majority had speech impairment. Most of them who came for consultation had mild to moderate severity of autism. The mean CARS scores was 33.63 (SD 2.97), social age in months was 36.39 (SD 14.43) and intelligence quotient was 81 (SD16.79). One fifth had seizures wherein only small portions of the people were on regular AEDs. $16.8 \%$ had family history of mental illness.

Table 3: Perinatal and Developmental Profile

\begin{tabular}{|l|l|}
\hline Variable & $\mathbf{N}(\%)$ \\
\hline Place of Delivery & \\
\hline Government public hospital & $74(54.0)$ \\
\hline Private hospital & $60(43.8)$ \\
\hline Home & $2(01.5)$ \\
\hline Not available & $1(00.7)$ \\
\hline Term of Delivery & \\
\hline Full term & $122(89.1)$ \\
\hline Pre term & $12(08.8)$ \\
\hline Not available & $3(02.1)$ \\
\hline Delivery Mode & \\
\hline Natural birth & $64(46.7)$ \\
\hline C section & $63(46.0)$ \\
\hline Forceps/ instruments used & $7(05.1)$ \\
\hline Not available & $3(02.2)$ \\
\hline & 4
\end{tabular}




\begin{tabular}{|l|l|}
\hline Birth Cry & \\
\hline Immediate & $103(75.2)$ \\
\hline Delayed & $31(20.7)$ \\
\hline Not available & $3(04.1)$ \\
\hline NICU & \\
\hline Yes & $32(23.4)$ \\
\hline No & $98(71.5)$ \\
\hline Not available & $6(05.1)$ \\
\hline Breast Fed & \\
\hline Yes & $107(78.1)$ \\
\hline No & $11(08.0)$ \\
\hline Not available & $20(13.9)$ \\
\hline Developmental Milestones & \\
\hline Age appropriate & $1(00.7)$ \\
\hline Delayed & $134(97.8)$ \\
\hline Not available & $2(01.5)$ \\
\hline Motor Milestones & \\
\hline Age appropriate & $88(64.2)$ \\
\hline Delayed & $47(34.3)$ \\
\hline Not available & $2(01.5)$ \\
\hline Speech Milestones & \\
\hline Age appropriate & $1(00.7)$ \\
\hline Delayed & $134(97.8)$ \\
\hline Not available & $2(01.5)$ \\
\hline & \\
\hline & \\
\hline
\end{tabular}

Table 3 shows the perinatal and developmental profile, nearly half the sample were born in government public hospital, majority were born full term, nearly half were caesarean section, two third had immediate birth cry, around one fourth were in the NICU and nearly three fourth was breast fed. Majority had delayed developmental milestones especially delayed speech millstones but only two third had delayed motor milestones.

\section{Table 4: Services}

\begin{tabular}{|l|c|c|}
\hline Variable & $\mathbf{N}(\%)$ & Median (Range) \\
\hline Receiving any services & & \\
\hline Yes & $83(60.6)$ & \\
\hline No & $48(35.0)$ & \\
\hline Not available & $4(04.9)$ & \\
\hline Where are they receiving services & & \\
\hline Government sector & $15(10.9)$ & \\
\hline Private sector & $70(51.1)$ & \\
\hline Not taking any services & $48(35.0)$ & \\
\hline Not available & $4(03.0)$ & \\
\hline
\end{tabular}




\begin{tabular}{|l|c|l|}
\hline Services Received & & \\
\hline Medical & $2(01.5)$ & \\
\hline Behaviour therapy, speech and occupational therapy & $1(00.7)$ & \\
\hline Special education & $1(00.7)$ & \\
\hline Special education, speech \& occupationaltherapy & $60(43.8)$ & \\
\hline Special education and speech therapy & $1(00.7)$ & \\
\hline Speech therapy & $2(01.5)$ & \\
\hline Speech and Occupational therapy & $7(05.1)$ & \\
\hline Occupational therapy & $6(04.3)$ & \\
\hline Physiotherapy & $1(00.7)$ & \\
\hline Not receiving any services & $48(35.0)$ & \\
\hline Not available & $8(06.0)$ & \\
\hline Attended Play School & & \\
\hline Yes & $47(34.3)$ & \\
\hline No & $78(56.9)$ & \\
\hline Not available & $12(08.8)$ & \\
\hline Disability Card & & \\
\hline Yes & $8(05.8)$ & \\
\hline No & $129(94.2)$ & \\
\hline Age of first contact with Department & & $79(58-113.9)$ \\
\hline Child started school & & $36(18-48)$ \\
\hline
\end{tabular}

Table 4 shows the details of the services that have been availed. It has been found that nearly half of the individuals were taking private services and one third attended play school. Two third were taking a combination therapy of special education, speech and occupational therapy. Only a very small group had disability card. The median age of first contact with the department was 79 months (Inter Quartile Range 58 - 113.9) and the child started schooling at a median age of 36 months (Range $18-48$ ).

\section{Table 5: Relationship of Variables with Severity of Autism}

\begin{tabular}{|l|l|l|l|}
\hline \multicolumn{1}{|c|}{ Variables } & \multicolumn{2}{c|}{ Severity of Autism } & P - Value \\
\hline & \multicolumn{1}{|c|}{ Mild/Moderate } & \multicolumn{1}{c|}{ Severe } & \\
\hline Consanguinity & & & \\
\hline Consanguineous & $28(96.6)$ & $1(3.4)$ & \\
\hline Non-consanguineous & $93(87.7)$ & $13(12.3)$ & 0.36 \\
\hline Birth Order & & & \\
\hline 1st & $73(90.1)$ & $8(9.9)$ & \\
\hline 2nd & $41(91.1)$ & $4(8.9)$ & $0.03^{*}$ \\
\hline 3rd & $7(87.5)$ & $1(12.5)$ & \\
\hline
\end{tabular}




\begin{tabular}{|l|l|l|l|}
\hline Place of Delivery & & & \\
\hline Government hospital/ PHC & $62(83.8)$ & $12(16.2)$ & \\
\hline Private hospital & $58(96.7)$ & $2(3.3)$ & $0.04^{*}$ \\
\hline Home & $2(100)$ & $0(0)$ & \\
\hline Term of Delivery & & & \\
\hline Full term & $112(91.8)$ & $10(8.2)$ & 0.09 \\
\hline Pre term & $9(75)$ & $3(25)$ & \\
\hline Delivery Mode & & & \\
\hline Natural birth & $56(87.5)$ & $8(12.5)$ & \\
\hline C section & $60(95.2)$ & $3(4.8)$ & 0.07 \\
\hline Forceps/ instruments used & $5(71.4)$ & $2(28.6)$ & \\
\hline Birth Cry & & & \\
\hline Immediate & $95(92.2)$ & $8(7.8)$ & 0.47 \\
\hline Delayed & $25(85.2)$ & $4(14.8)$ & \\
\hline NICU & & & \\
\hline Yes & $26(81.3)$ & $6(18.8)$ & $0.02^{*}$ \\
\hline No & $93(94.9)$ & $5(5.1)$ & \\
\hline Breast Fed & & & \\
\hline Yes & $98(91.6)$ & $9(8.4)$ & 0.08 \\
\hline No & $8(72.7)$ & $3(27.3)$ & \\
\hline Developmental Milestones & & & \\
\hline Age appropriate & $1(100)$ & $0(0)$ & 0.90 \\
\hline Delayed & $121(90.3)$ & $13(9.7)$ & \\
\hline Motor Milestones & & & \\
\hline Age appropriate & $81(92)$ & $7(8)$ & 0.27 \\
\hline Delayed & $41(87.2)$ & $6(12.8)$ & \\
\hline Speech Milestones & & & \\
\hline Age appropriate & $0(0)$ & $12(9)$ & \\
\hline Delayed & $121(91)$ & & \\
\hline Mothers Feed & & & \\
\hline$<12$ Months & & & \\
\hline$>12$ Months & & & \\
\hline & & & \\
\hline
\end{tabular}

${ }^{\star}$ Significant

Table 5, shows that most of the individuals were of 1 st birth order. Individuals with mild to moderate autism were more often born in government public hospital. Individuals with severe autism were significantly less likely to be breast fed than those with mild autism. 


\section{DISCUSSION}

This study has shown that $63.5 \%$ of individuals with ASD have intellectual disability which corresponds with the study by Bouras ${ }^{(6)}$ where in their study they have found that nearly $70 \%$ of people with PDD also have ID. Majority also had speech impairment. The high prevalence of intellectual disability and speech impairment in the study could be as it is a tertiary care teaching hospital hence children with more disability are brought in by their parents for seeking treatment and also for availing governmental benefits.

The study shows that only $5.8 \%$ had disability card when they first made contact with the department while a huge proportion of individuals with ASD in the study have disability hence we need to think of efficient ways like conducting more awareness and screening camps in schools and communities to reduce this huge gap.

In the study males constituted the majority (86.1\%) which is consistent with the studies of Fombonne ${ }^{(7)(8)(9)}$ where the estimates of a male to female ratio is approximately $4.3: 1$. It has been found that $19.7 \%$ of the children in this study had seizures which has also been found in the study by Tuchman ${ }^{(10)}$ where they found that the conservative estimate of epilepsy in autism is approximately $25 \%$. Only $8.8 \%$ were on AED in the study. This shows the need to liaison with neurology department as the seizures has an overall impact on the individual and it needs to be controlled.

Nearly $43.8 \%$ in the study took combination therapy of special education, speech and occupational therapy and Subramanyam ${ }^{(11)}$ has also recommended interdisciplinary therapy. In the study the mean age of the individual with ASD at the first contact with the department was 79 months, which is quite late, as children as young as 16 months can be screened for $\mathrm{ASD}^{(12)}$ and clearly the value for early detection would help in supporting the family to obtain early intervention which would help in effective cognitive and social learning and would also reduce the burnout for the family. Hence there is a need to focus on awareness and also on strengthening the pathways to help them avail services.

The majority of the 1st birth order (90.1) in the study had mild to moderate autism. This indicates that at the time when they came in for consultation they were first born, a follow up study can throw more light if the family decided to have another child and whether they underwent genetic counselling. It has been found that the majority of the individuals with mild to moderate autism were born in government public hospital. This could be because most of them belong to the LSES and mostly government public hospital is the preferred choice to deliver and to take treatment. Nearly half of the individuals with severe autism were breast fed less than 12 months. It would be interesting to explore this aspect and understand the mental health of the mother and also the impact of breastfeeding on improving the socialisation.

\section{CONCLUSION}

Two third of individuals with ASD also have Intellectual Disability, more than half the mothers of individuals with ASD did not breastfeed beyond 12 months, about one third of individuals with ASD have not availed any kind of services. It takes arounds 6 years of age for the parents/ individuals with ASD to seek treatment help.

This study is an attempt to understand the socio demographic and clinical characteristics of the individuals with ASD. As there are limitations (hospital based study and perusal of records with missing data) a community based follow up would throw better clarity on overall clinical picture. That in turn will help in better policy making and awareness, early intervention and treatment protocol. 


\section{References}

1 American Psychiatric Association: Diagnostic and Statistical Manual of Mental Disorders: Diagnostic and Statistical Manual of Mental Disorders, Fifth Edition.(2013) Arlington, VA: American Psychiatric Association.

2 Rudra A, Belmonte MK, Soni PK, Banerjee S, Mukerji S, et al. Prevalence of autism spectrum disorder and autistic symptoms in a school-base cohort of children in Kolkata, India. Autism Research. 2017; 10:15971605.

3 Raina SK, Vishav Chander, Ashok K Bhardwaj, Dinesh Kumar, Seema Sharma, et al. Prevalence of Autism Spectrum Disorder among Rural, Urban, and Tribal Children (1-10 Years of Age). Journal of Neurosciences in Rural Practice. 2017; 8:368-374.

4 Schopler E, Reichler RJ, DeVellis RF, Daly K. Toward objective classification of childhood autism: childhood autism rating scale (CARS). Journal of Autism and Developmental Disorders. 1980; 10(1):91103.

5 Russell PS, Daniel A, Russell S. et al. Diagnostic accuracy, reliability and validity of childhood autism rating scale in India. World Journal of Pediatrics. 2010; 6(2): 141-147.

6 Bouras N, Holt G, Day K \& Dosen A. Mental Health in Mental Retardation. The ABC for Mental Health, Primary Care and Other Professionals. 1999; WPA Section of Mental Retardation, London.

7 Fombonne E. Epidemiological surveys of autism and other pervasive developmental disorders: An update. Journal of Autism and Developmental Disorders. 2003; 33(4):365-382.

8 Fombonne E. The changing epidemiology of autism. Journal of Applied Research in Intellectual Disabilities. 2005; 18(4):281-294.

9 Fombonne E. Epidemiological surveys of pervasive developmental disorders. In FR Volkmar (Ed.), Autism and pervasive developmental disorders (2nd Ed), New York, Cambridge University Press. 2007; pp. 33-68.

10 Tuchman R, Rapin I. Epilepsy in autism. Lancet Neurology 2002; 1:352-358.

11 Subramanyam AA, Mukherjee A, Dave M, Chavda K. Clinical practice guidelines for autism spectrum disorders. Indian Journal of Psychiatry. 2019; 61(Suppl_2):S254-269.

12 Towle PO \& Patrick PA. Autism Spectrum Disorder Screening Instruments for Very Young Children: A Systematic Review. Autism research and treatment. 2016; ss02: 1-29. 